\section{Leonid Zamikhovskyi, Olena Zamikhovska, Volodymyr Pavlyk}

\title{
RESEARCH OF THE CHARACTERISTICS OF ACOUSTIC PROCESSES USING WAVELET TRANSFORMATION FOR DETECTING A DIAGNOSTIC SIGN OF THE TECHNICAL STATE OF GAS PUMPING UNITS
}

The object of research is the degradation processes that take place in gas-pumping units (GPU) during its longterm operation and lead to the appearance of defects and, as a result, to a change in its technical state. Today, methods of parametric and vibration diagnostics are used to determine the technical condition of the GPU. To identify diagnostic signs of the technical state of the GPU, various transformations are used, in particular the wavelet transforms used in vibration processing that accompany the operation of the GPU and their technological parameters.

At the same time, in the study of the diagnostic signs of the technical state of the GPU, the acoustic processes accompanying the operation of the GPU, which can be more informative in comparison with the vibration ones, were practically not considered.

The developed experimental research methodology and their technical support made it possible to record the acoustic processes accompanying the operation of the gas compressor unit type GTK-25-i of the Nuovo Pignon company (Italy). In the course of the experimental studies, the realizations of the acoustic processes of the GPU were obtained for its three states - «nominal», «defective» and «current».

Further studies of acoustic processes for three states of the GPU type GTK-25-i and using the wavelet transform showed that by the appearance of the wavelet spectrograms it is difficult to notice the difference in the appearance or disappearance of various frequency components depending on the technical state of the GPU. To obtain quantitative indicators of this dependence, a discrete wavelet transform was carried out, which makes it possible to identify characteristic trends in the change in noise values at different scales. The values of the approximation norm and the detail norms in relation to the signal norm (in percent) were obtained for a five-level wavelet decomposition with datasets. A linear dependence of the norm of the wavelet-component of the fifth-order detailing on the operating time of GPU type GTK-25-i and (changes in the technical state), which can be taken as a diagnostic sign of its technical state, has been established.

The investigated diagnostic feature can be used as the basis for the method of diagnosing the technical state of GPU type GTK-25-i based on the characteristics of its acoustic process using the wavelet transform. An approach to identifying a diagnostic sign of the technical state of a GPU type GTK-25-i is considered based on the characteristics of acoustic processes using a wavelet transform can be used to identify a diagnostic sign of a condition for any type of GPU.

Keywords: gas pumping unit, acoustic process, experimental research, wavelet transformations, diagnostic feature, technical condition.

\section{Introduction}

To determine the technical condition of gas pumping units (GPU) during operation, a significant number of diagnostic methods are used, among which the most common are parametric and vibration diagnostics. In order to identify diagnostic signs, various transformations are used, which are used in vibration processing, which accompany the operation of the GPU and their technological parameters.

Wavelet transforms are one of such transformations. In [1], the concept of wavelets is given and their use in practical calculations and various applications is briefly described without rigorous mathematical statements, references to which are given in the list of cited references (92 titles). Work [2] is one of the first to use wavelet transform for processing vibration signals. The paper discusses the theoretical foundations of wavelet analysis in an accessible form for perception and understanding, and also gives examples of its application in the practice of analyzing machine vibration. The paper also outlines the principles of wavelet-oriented techniques for vibroacoustic diagnostics of machines. 
To control the technical condition of GPU and their units, as well as gas turbine engines (GTE) in [3], a model for diagnosing GTE units is considered, which differs from the existing ones by using continuous wavelet analysis, crossspectral analysis and S-discriminant. The results of experimental studies of the developed methods for analyzing vibration signals presented in the work showed their effectiveness in identifying signs of wear of engine components. In [4], a brief overview and comparison of various transformations that can be performed when processing vibration of an air compressor to assess its three states is given. The following transforms were used: Fast Fourier transform, discrete cosine transform, autocorrelation function, Cohen class distributions, $\mathrm{S}$-transforms and various wavelet transforms.

An algorithm for diagnosing air compressor malfunctions based on the use of wavelet transform and artificial neural networks is considered in [5]. At the same time, there are no references in the work of the results of the practical implementation of the developed algorithm. The paper [6] examines the features of using the wavelet transform to determine the diagnostic feature of the technical state of the GPU based on the results of processing vibroacoustic processes that characterize its operation for three qualitative states of the GPU. The use of the wavelet transform is due to the fact that its main area of application is the analysis and processing of signals and functions that are nonstationary in time or inhomogeneous in space. Unlike spectral analysis, in the case of wavelet transform, it is not necessary to modify the algorithms depending on whether the process under study is stationary or non-stationary, constituent or complex. The analysis method does not change depending on the characteristics of the process. On the contrary, the wavelet transform allows to determine the structure of the signal, to perform its division into quasi-stationary sections [7]. At the same time, the analysis results contain not only the general frequency characteristic of the signal (the distribution of the signal energy by frequency components), but also information about certain local coordinates on which certain groups of frequency components are found, or on which rapid changes in the frequency components of the signal occur [8]. In [7], examples of the use of the wavelet transform for the study of processes in the elements of gas turbine engines (GTE) for monitoring the technical condition of GTE bearings, identifying the development of the phenomenon of the surge of a GTE compressor, etc. are given.

Thus, to identify diagnostic signs of the technical condition of the GPU and GTE, wavelet transforms are used to process the vibration processes that accompany their operation. At the same time, in the study of the diagnostic signs of the technical state of the GPU, the acoustic processes accompanying the operation of the GPU can be more informative in comparison with the vibration ones, practically were not considered. An exception is the work [9], but in it the processing of the acoustic process was carried out using the Fourier transform. In this regard, the problem of using the wavelet transform for processing acoustic processes accompanying the operation of the GPU is urgent.

Thus, the object of research is the degradation processes that take place in the GPU during its long-term operation and lead to the appearance of defects and, as a consequence, to a change in its technical state.

The aim of research is to study the characteristics of acoustic processes using the wavelet transform to identify diagnostic signs of the technical state of the GPU.

\section{Research methodology}

The experimental research methodology provided for the recording of acoustic processes accompanying the operation of the GPU type GTK-25-i of the Nuovo Pignon company (Italy), and installed at the CS-39 «U-P-U» of the Bogorodchansk linear production department of main gas pipelines (Bogorodchany, Ivano-Frankivsk region, Ukraine) LLC «Operator of the gas transportation system of Ukraine» (Kyiv, Ukraine). For this, an acoustic control system was used, implemented on a sensitive electret microphone [10], mounted in an explosion-proof housing. The microphone was installed in the area of bearing No. 1 directly at the blades of $0,1,2$ steps of the GPU type GTK-25-i axial compressor, since they are the most loaded elements. The Steinberg Nuendo 3.2.0 software package was used to organize on-line recordings and process electret microphone signals. In accordance with the experimental research methodology, the original files of the .mat format with the recording of acoustic signals to be processed were obtained.

The duration of three records for the states of GPU No. 3 «defective», «nominal» and «current» - was $10 \mathrm{~s}$ each with a sampling rate of $44.1 \mathrm{kHz}$, which is the standard for recording sound signals.

The recording capacity is 16 bits (values from -32768 to +32768 ). The recording level was $-35 \mathrm{~dB}$. In the software used to record noise and vibration, a $0 \mathrm{~dB}$ level corresponds to an input signal of $0.775 \mathrm{~V}$ from an amplifier. The signal level when receiving audio signals from the amplifiers was significantly higher. Therefore, in order to avoid the phenomenon of «clipping» (cutting off) the amplitude of the signals, a software reduction in the recording coefficient was applied by $20 \mathrm{~dB}, 30 \mathrm{~dB}$ and $35 \mathrm{~dB}$, respectively.

\section{Research results and discussion}

Let's use wavelet transforms to determine signal characteristics and track changes in signal parameters over time. For the basic function, let's choose a fourth-order symletwavelet (sym4 function in Matlab, Fig. 1) [6]. Wavelets of the family of symlets are a modified version of Daubechies wavelets with better symmetry.

This family of wavelets is used in a number of tasks, namely: reducing the level of signal noise, forecasting [11] and processing signals and images [12]. The first stage of processing was the construction of spectrograms of the acoustic signal.

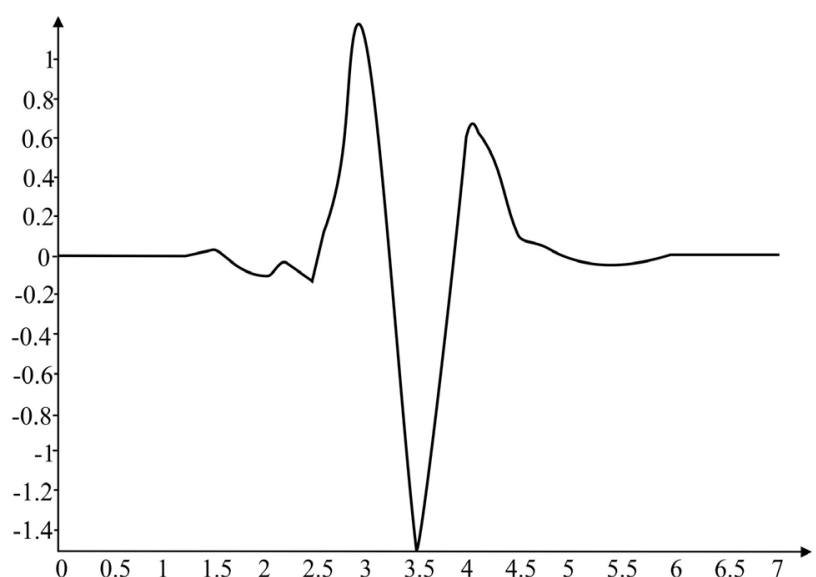

Fig. 1. Wavelet function sym4 
The sequence of processing operations is as follows:

- loading data into Matlab environment;

- selection of a data array with a length of 532 characters;

- construction of spectrograms using the fourth order symlet-wavelet;

- output of the spectrogram for each of the data sets.

The resulting spectrograms are shown in Fig. 2.
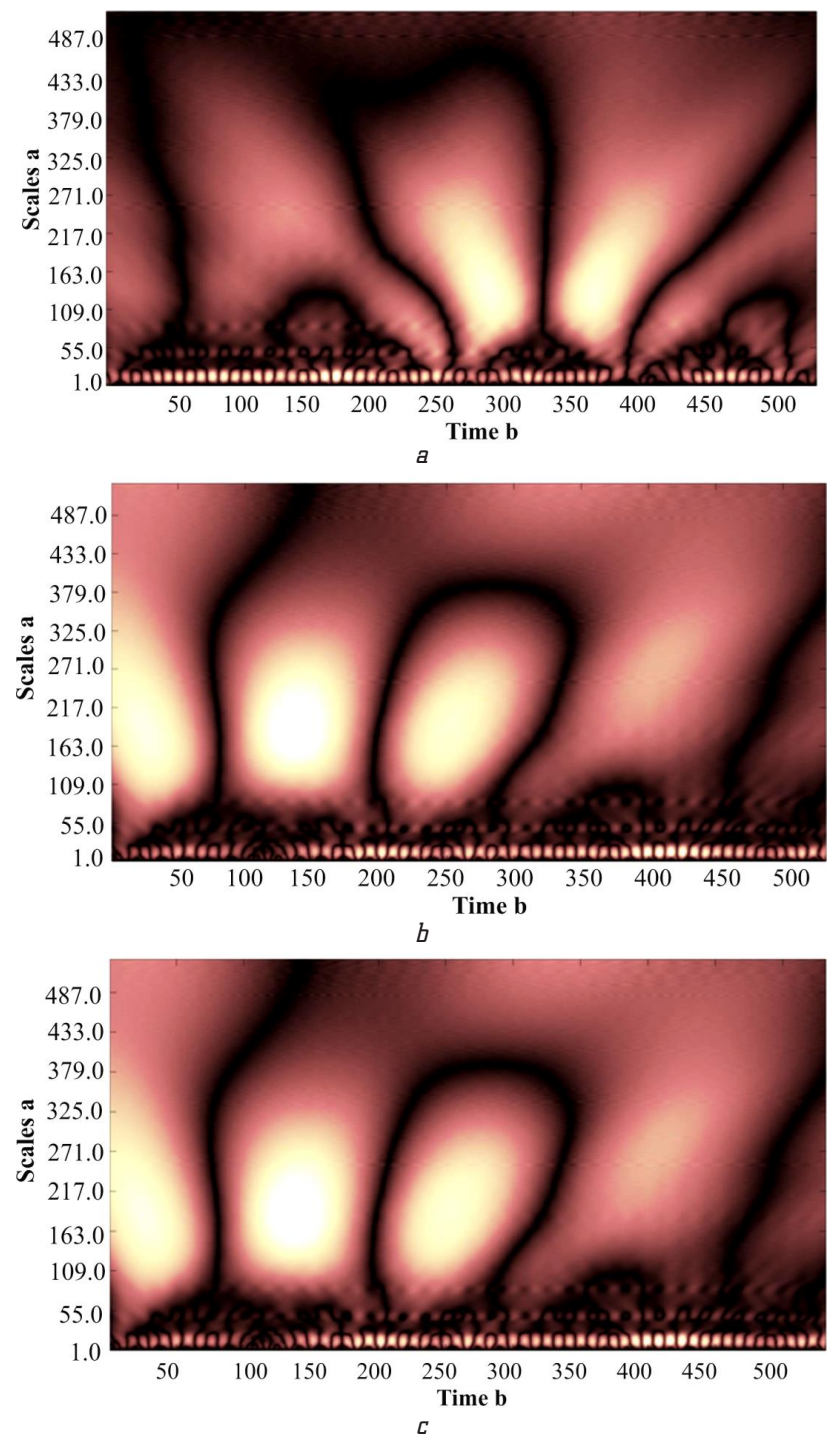

Fig. 2. Spectrograms of sampling from acoustic signal records: $a-$ «defective», $b-$ «nominal», $c-$ «current» states of the gas compressor unit No. 3

As can be seen from the graphs in Fig. 2, on small scales (1-28 values), the wavelet spectrogram of data sets for the «nominal» state of the GPU almost completely retains its periodicity. At the same time, the data set for the «defective» state has some deviations in the range of values $370-530$ in time count.

On scales $28-55$ in the spectrogram in Fig. 2, $a$, there is a deviation from the spectrograms in Fig. 2, $b, c$. Since the high-frequency component disappears at values of 200-500, and the spectrogram in this region is described by 5 peak values. On further scales, it can be seen that in the values of 200-350 in the spectrograms in Fig. 2, b, c, there is a smoothed peak increase. Whereas in Fig. 2, $a$ on a large scale (400-480), this increase has an irregular shape. In addition, on large scales (500 and higher) in the spectrogram in Fig. 2, $a$, an insignificant periodic component appears, while in the other two spectrograms it is almost not expressed.

Analyzing the obtained spectrograms, it is possible to conclude that they have a lot of similarities. At the same time, when studying them on small and large scales, differences in the appearance or disappearance of various frequency components are noticeable depending on the «current» state.

To obtain quantitative indicators of this dependence, let's carry out a discrete wavelet transform. In the case of this study, this operation allows to identify characteristic trends in the change in noise values at different scales. This is achieved through the operation of decomposition into components of the wavelet transform (Fig. 3).

A typical picture of the wavelet decomposition of a signal by a fourth-order symlet-wavelet for 5 components is shown in Fig. 4.

As can be seen from the graphs in Fig. 4, with the separation of each of the components $d 1-d 5$, the highfrequency component is filtered, with the residual signal $a 5$ being inherently aperiodic. Table 1 shows the values of the approximation norm and the detail norms in relation to the signal norm (in percent) for the five-level wavelet decomposition according to the data sets described above. The characteristics of each of the data sets were the GPU operating time after repair per hour.

As can be seen from the data in Table 1, on the fifth component of wavelet decomposition detailing, an increase in the value of the norm is observed depending on the operating time (technical state of the GPU). Let's present the obtained data on D5P on the graph in the form of points (Fig. 5).

As seen in Fig. 5, there is a tendency to a linear increase in the value of the norm of the wavelet component of the fifth order detailing relative to the operating time. Let's carry out an approximation of the obtained data (Fig. 5):

\section{$D 5=0.0005 t+6.7414$,}

where $t$ - GPU operating hours.

Approximation reliability $\mathrm{R} 2$ is 0.9954 , which is a high indicator.

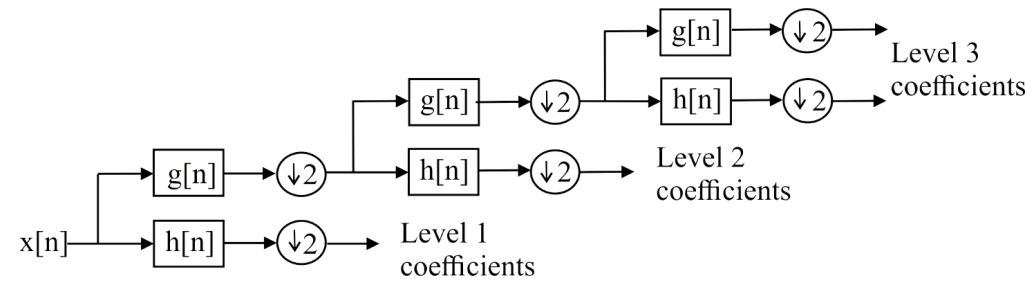

Fig. 3. Wavelet decomposition tree (bank) 


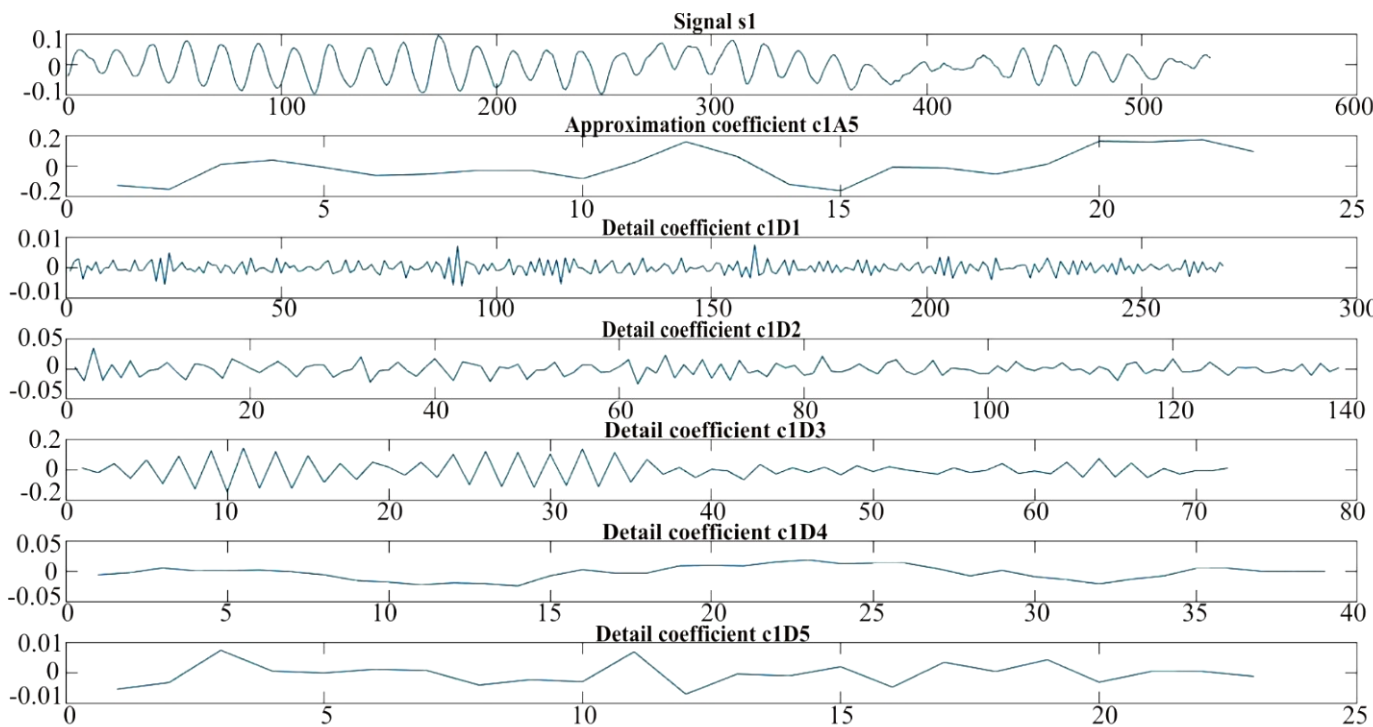

Fig. 4. Typical picture of a schedule for a fourth-order symlet-wavelet

Table 1 composition of the acoustic signal, the change in which from

The value of the approximation norm and the detail norms in relation to the signal norm (in percent) for a five-level wavelet decomposition

\begin{tabular}{|c|c|c|c|}
\hline $\begin{array}{c}\text { Decomposition } \\
\text { component/ratio of } \\
\text { component norm to } \\
\text { signal norm, \% }\end{array}$ & $\begin{array}{c}\text { «Nominal» } \\
\text { state of the } \\
\text { GPU - 0 ope- } \\
\text { rating hours }\end{array}$ & $\begin{array}{c}\text { «Current» state } \\
\text { of the GPU - } \\
2500 \text { operating } \\
\text { hours }\end{array}$ & $\begin{array}{c}\text { «efective» state } \\
\text { of the GPU - } \\
16000 \text { operat- } \\
\text { ing hours }\end{array}$ \\
\hline 5 & 3.3358 & 0.2376 & 0.9781 \\
\hline A7 & 37.4571 & 20.1177 & 30.6366 \\
\hline$D 1$ & 3.0508 & 5.5549 & 3.3212 \\
\hline$D 2$ & 18.5974 & 31.3913 & 12.0741 \\
\hline$D 3$ & 56.9395 & 68.2173 & 60.435 \\
\hline$D 4$ & 70.5102 & 61.9016 & 70.5607 \\
\hline$D 5$ & 6.9896 & 7.6159 & 14.2671 \\
\hline
\end{tabular}

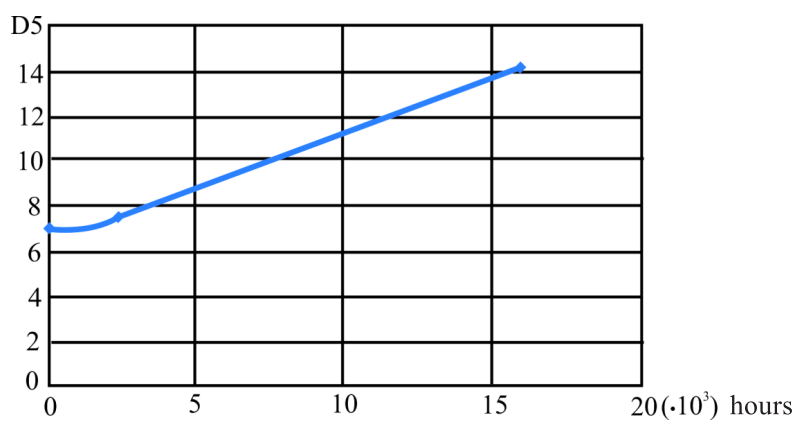

Fig. 5. Graph of the ratio of the norm of the wavelet component of fifth-order detailing to the operating time of gas-pumping units

\section{Conclusions}

Experimental studies of acoustic processes accompanying the operation of the GPU for its three states - «nominal», «defective» and «current», which made it possible to obtain data samples for their further processing. The processing of the obtained experimental data using the wavelet transform made it possible to obtain a diagnostic indicator of the technical state of the GPU type GTK-25-i the fifth component of the detailing of the wavelet de- the GPU operation period (changes in its technical state) is described by a linear equation. The investigated diagnostic feature can be used as the basis for the method of diagnosing the technical state of the GPU based on the characteristics of the acoustic signal using the wavelet transform.

An approach to identifying a diagnostic feature based on the characteristics of acoustic processes using a wavelet transform is considered. It can be used for any GPU type.

\section{References}

1. Dremin, I. M., Ivanov, O. V., Nechitailo, V. A. (2001). Veivlety i ikh ispolzovanie. Uspekhi fizicheskikh nauk, 171 (5), 465-501.

2. Prygunov, A. I. (2003). Veivlety v vibratsionnoi dinamike mashin. Available at: http://www.vibration.ru/wavelet.shtml

3. Iur, T. V., Kharitonov, V. M., Dubrovin, V. I. (2013). Model otsinki tekhnichnogo stanu vuzliv GTD za parametrami vibratsii $\mathrm{z}$ vikoristanniam veivlet-peretvorennia. Aviatsionno-kosmicheskaia tekhnika i tekhnologii, 10 (107), 177-182.

4. Verma, N. K., Gupta, R., Sevakula, R. K., Salour, A. (2014). Signal transforms for feature extraction from vibration signal for air compressor monitoring. TENCON 2014 - 2014 IEEE Region 10 Conference. doi: http://doi.org/10.1109/tencon.2014.7022275

5. Yang, W. S., Su, Y. X., Chen, Y. P. (2019). Air compressor fault diagnosis based on lifting wavelet transform and probabilistic neural network. IOP Conference Series: Materials Science and Engineering, 657, 012053. doi: http://doi.org/10.1088/1757-899x/657/1/012053

6. Zamikhovskyi, L. M., Ivaniuk, N. I., Pavlyk, V. V. (2017). Vykorystannia veivlet-peretvorennia dlia vyznachennia tekhnichnoho stanu hazoperekachuvalnykh ahrehativ. Suchasni prylady, materialy i tekhnolohii dlia neruiniznoho kontroliu i tekhnichnoi diahnostyky mashynobudivnoho i naftohazopromyslovoho obladnannia. IvanoFrankivsk, 132-133

7. Gryzlova, T. P., Piralishvili, G. Sh., Shepel, V. T. (2006). Metodicheskoe i programmnoe obespechenie obrabotki nestatsionarnykh protsessov na osnovanii wavelet-analiza. Vestnik dvigatelestroeniia, 3, 138-143.

8. Nakonechnyi, A. Y., Lahun, I. I., Veres, Z. Ye., Nakonechnyi, R. A., Fedak, V. I.; Nakonechnyi, A. Y. (Ed.) (2020). Teoriia i praktyka obrobky syhnaliv u malokhoylovii (wavelet) oblasti. Lviv: Rastr-7, 470.

9. Zamikhovskii, L. M., Pavlyk, V. (2014). Issledovanie diagnosticheskikh priznakov tekhnicheskogo sostoianiia gazoperekachivaiuschikh agregatov GTK - 25i firmy Nuovo-Pinone. Molodoi uchenii, 15 (74), 75-79

10. Pavlyk, V. V. (2012). Napriamky pidvyshchennia efektyvnosti ekspluatatsii hazoperekachuvalnykh ahrehativ v umovakh Bohorodchanskoho LVUMH. Naukovi visti, 2 (22), 44-49.

11. Swee, E. G. T., Elangovan, S. (1999). Applications of symlets for denoising and load forecasting. Proceedings of the IEEE 
Signal Processing Workshop on Higher-Order Statistics. SPWHOS '99. doi: http://doi.org/10.1109/host.1999.778717

12. Bultheel, A., Huybrechs, D. (2014). Wavelets with applications in signal and image processing. Available at: https://people. cs.kuleuven.be/ daan.huybrechs/teaching/wavelets2014.pdf

Leonid Zamikhovskyi, Doctor of Technical Sciences, Professor, Department of Information and Telecommunication Technology and Systems, Ivano-Frankivsk National Technical University of Oil and Gas, Ivano-Frankivsk, Ukraine, e-mail: leozam@ukr.net, ORCID: http://orcid.org/0000-0002-6374-8580
Olena Zamikhovska, PhD, Associate Professor, Department of Information and Telecommunication Technology and Systems, IvanoFrankivsk National Technical University of Oil and Gas, IvanoFrankivsk, Ukraine, e-mail: elenazam@meta.ua, ORCID: http:// orcid.org/0000-0003-0775-0472

Volodymyr Pazlyk, Department of Information and Telecommunication Technology and Systems, Ivano-Frankivsk National Technical University of Oil and Gas, Ivano-Frankivsk, Ukraine, e-mail: vpawlyk@ukr.net, ORCID: http://orcid.org/0000-0002-9979-6496

UDC 656.96

DOI: 10.15587/2706-5448.2021.225521 Article type «Reports on Research Projects»

\section{Nataliia Pavlova, Svitlana Onyshchenko}

\section{DEVELOPMENT AND RESEARCH OF A MODEL FOR OPTIMIZING THE COMPOSITION OF A PROJECT-ORIENTED FORWARDING COMPANY' SUPPLIERS}

The object of this research is the composition of the suppliers of a project-oriented transport and forwarding company. The work is aimed at determining the composition of the suppliers of a project-oriented transport and forwarding company, the purpose of which is to obtain a synergistic effect, which manifests itself in reducing the costs of performing individual operations of the transport process while meeting local requirements for each project.

This study proposes an optimization model that allows to determine the composition of suppliers of a project-oriented organization in order to obtain the maximum systemic effect - a synergistic effect. The proposed approach is based on the creation of a virtual project management office, the work of which is based on the corresponding information system. The proposed model is a flexible tool that allows to quickly form the composition of suppliers of a projectoriented company. The model is developed for the service sector and, in particular, for the transport industry, where suppliers are not responsible for material objects, resources, but for services, the set of which forms the essence of the project. Thus, the product of the project and its parameters in such a situation are directly formed due to the specifics of suppliers and the parameters of their services. For the transport industry, this approach has not been used before and can serve as a theoretical basis for building a project-oriented management system in the transport sector. The synergistic effect taken as a basis in this model provides the greatest difference between the «declared» delivery costs and the «actual» ones, which are formed taking into account the amount of work for all projects. Since the freight forwarding company is the «holder» of the portfolio of all deliveries/projects, a certain part of the synergy effect can be used to reduce delivery costs for customers in order to increase competitiveness and attractiveness.

Experimental studies have substantiated the reliability of the results of the developed model and confirmed its practical applicability. This model is quite universal and can be supplemented with restrictions that take into account the specifics of a project-oriented organization, its projects and requirements for suppliers.

Keywords: synergistic effect, portfolio of projects, distribution of scope of work, virtual project management office.

\section{Introduction}

The project-oriented approach to the management of companies (organizations, enterprises) is the leading modern management concept [1]. The effectiveness of this concept has been proven by the practice of use in various fields of activity, regardless of whether the organization is commercial or not, its activities are related to production or services, etc.

The project approach to the organization of operational activities, which forms the basis of project-oriented mana- gement, in contrast to the classical functional approach, implies focus on the result of the entire project, and not on the result of performing individual functions within the current (operational) activities of companies. At the same time, the responsibility for the final result increases the motivation for the staff within the framework of their involvement in a particular project. The need to assess and monitor the use of resources throughout the project, and not for individual operations of the production process, determines an adequate assessment of the effectiveness 